UK. Journal of Psychiatric and Mental Health Nursing, 12, 527-535.

JONES, M., BENNET, J., LUCAS, B., MILLER, D. \& GRAY, R. (2007) Mental health nurse supplementary prescribing: experiences of mental health nurses, psychiatrists and patients. Journal of Advanced Nursing $59,488-496$

KAAS, M. J. \& MARKLEY, J. M. (1998) A national perspective on prescriptive authority for advanced practice psychiatric nurses. Journal of American Psychiatric Nurses Association, 4 190-198.

KAAS, M. J., DAHL, D., DEHN, D. \& FRANK, K. (1998) Barriers to prescriptive practice for psychiatric/ mental health clinical nurse specialists. Clinical Nurse Specialist, 12, 200-204.

LATTER, S., MABEN, J., MYALL, M., COURTENAY, M., YOUNG, A. \& DUNN N. (2005) An Evaluation of Extended Formulary Independent Nurse Prescribing. Department of Health (http://www.dh.gov.uk/assetRoot/ 04/11/40/86/04114086.pdf)

MEHTA, S., SALVAJI, A. \& ABED, R. (2007) Roles of general adult psychiatrists in follow-up clinics Psychiatric Bulletin, 31, 381-384.

NATIONAL PRESCRIBING CENTRE (2003) Supplementary Prescribing. A Resource to Help Healthcare Professionals to Understand the Resources and Opportunities. NPC (http://www.npc.co.uk/publications/ healthcare_resource.pdf).

NATIONAL PRESCRIBING CENTRE (2005) Training Non-medical Prescribers in Practice: A Guide to Help Doctors Prepare for and Carry Out the Role of Designated Medical

Practitioner. NPC (http://www.npc. co.uk/pdf/designated_medical_ practitioners_guide.pdf).

NATIONAL PRESCRIBING CENTRE, NATIONAL INSTITUTE FOR MENTAL HEALTH IN ENGLAND \& DEPARTMENT OF HEALTH (2005) Improving Mental

Mona-Lisa Kwentoh Specialty Registrar (ST4), Teesside and Easington Early Intervention Service, Stockton onTees, *Joe Reilly Director, Mental Health Research Centre, Durham University, Wolfson Research Institute, Queen's Campus, University Boulevard, Stockton onTees TS176BH, email: j.g.reilly@durham.ac.uk

\title{
Role confusion, values-based practice and the demise of the generalist
}

\section{SUMMARY}

As multidisciplinary work becomes less about profession than role and more about specialties than generalism, generalist roles are at risk of being overlooked (from a systemic perspective) and undervalued (from a values-based practice perspective). This article re-examines these issues and points to some practical implications of recovering the generalist role in mental health work.
Whatever happened to the generalist? Healthcare has become increasingly specialised over past decades yet surprisingly little has been written about the demise of generalism in mental health - for example, it gets very little attention in the New Ways of Working documentation (Royal College of Psychiatrists et al, 2005).

The roles of generalist and specialist have a reciprocal relationship to one another. This article is an attempt to respect (literally to 'look again' at) the idea of generalism as a role (or set of roles). First, roles will be defined as forms of enacted values and then further considered as values that often exist in tension with one another. An example of a value tension is when a service user's need to be protected (because of the consequences of having a mental disorder) comes into conflict with their therapeutic need for personal autonomy and development. We could summarise this tension as safety $v$. growth. This article will explore how this sort of tension can get unhelpfully acted out systemically when the generalist role gets lost within multidisciplinary teams whose specialist members may have different attitudes to treatment approaches (Lepping et al, 2004).

\section{Historical context}

Besides the irrepressible growth of specialties, a number of other trends are worth noting in the field of contemporary mental health service development. In multidisciplinary teams, the profession of origin of the team member does not exclusively demarcate their skills and competencies. There are considerable and growing overlaps. Sometimes nurses prescribe, doctors use activity schedules, occupational therapists care coordinate. There is general acknowledgement that old hierarchical structures have left consultant psychiatrists with an over-extended set of responsibilities, particularly general adult psychiatrists. New Ways of Working (Royal College of Psychiatrists et al, 2005 ) offers ideas to limit this burden (e.g. making consultants more consultative), although tensions may still exist inside teams where there are differential rates of pay status and responsibility.

A second trend that is clearly evident is the tighter level of professional regulation and managerial oversight, especially for doctors. Part of the regulatory approach has been to promulgate best practice based on best evidence (e.g. by the National Institute for Health and Clinical Excellence (www.nice.org.uk)). This is an expression of a desire to have a more standardised approach based on certain values: the attempt to deliver fair, safe and effective treatments while reducing risks of eccentric, unaccountable clinical practice.

\section{Roles and values}

It is worth considering from a systemic perspective what effect these trends are having on the consultant role. A 
role can be considered as a set of connected behaviours, rights and obligations as conceptualised by people in a

opinion \& debate given social situation. Roles imply, and therefore reciprocate and elicit other roles: they act 'in relation to'. In that sense they can be considered as bipolar social constructs. One pole cannot be considered in isolation to the other. The health paradigm here would be the sick role that underpins the medical relationship (Parsons, 1951). Because certain roles contain rights and obligations (the role of a doctor, for example), they are not just factual descriptions. They contain values. In that sense roles can be considered as forms of enacted values (Table 1).

Considerable effort has been made to look at the value base of mental health practice. Indeed, the proposal to set so-called values-based practice alongside what has become an unimpeachable ideal of evidence-based practice is gaining wider currency (Woodbridge \& Fulford, 2004). There are no agreed theoretical frameworks that underpin mental health ethics (Bloch \& Green, 2006) but there is broad consensus about what ideals should be aspired to across professions. Accordingly each regulatory body has produced lists of high-minded but probably unmemorable overlapping values.

Healthcare has many situations in which value tensions exist regardless of medical speciality (e.g. around confidentiality). Unique to mental healthcare work there is often a value tension at the heart of the work, it is the elephant in the room. Not only are clinicians employed to promote service users' recovery from mental distress (what could be termed a change or growthoriented therapeutic focus), they are also required to consider if they (or others) need to be protected from the consequences of their own behaviour (a risk-reducing or stabilising focus). Sometimes these aims conflict (e.g. when deciding whether to compulsorily admit someone with emotionally unstable personality disorder). Thus roles, being forms of enacted values, may be in tension. We can imagine that sometimes, unlike an approved social worker, a psychologist may oppose compulsory admission (but not have to do the Mental Health Act assessment). Like parents bringing up children into adulthood, safe, but also enabled, professionals aim to promote safety (which might mean taking some responsibility for a service user's possible behaviour) as well as to help them master distress and encourage change (which may necessitate giving responsibility).

\section{Implications for generalism}

As mental health roles become ever more specialist, generalist roles become organisationally and conceptually at risk because their value base is going unnoticed. Perhaps part of the reason for this is because there is insufficient systemic awareness of a structural value tension underpinning them: the safety $v$. growth dilemma. From a systemic perspective, the generalist occupies a unique position. Indeed, it is the systemic position that defines the generalist role; it is not simply about possessing a breadth of skills or competencies. Generalists are individuals or subgroups acting in a certain systemic role. Examples include general practitioners (GPs), care coordinators, consultant general adult psychiatrists and community mental health teams. The systemic position has the central perspective: oversight. Its position is the one to which the patient returns to, as it were the 'holding' relationship. Furthermore, there are hierarchies of generalism in terms of the oversight given to a particular patient (say from GP to care coordinator).

It is important to note that all clinicians may, at times, be generalists or specialists, even with the same service user. Systemically each role has a characteristic role perspective. A generalist role has an oversight perspective, overseeing a patient beyond just their expressed wishes and desires, into a notional region we can call their 'best interests' (which they might disagree with). A best interest perspective takes into account safety. Paradigmatically in mental health work it occurs in Mental Health Act assessments. Oversight also involves a breadth of perspective and therefore implies a holistic broad assessment. The care coordination needs assessment process enshrines this

In contrast, specialist roles may have focused role perspectives in relation to the service user - not simply 'best interests'. Whereas systemically generalist roles are centrally placed, specialist roles are, as it were, more peripheral. Patients are sent by a process of delegation or referral. At a dyadic level, the relational roles of specialist-service user may not always work from a simple best interest, holistic value base. At first sight this may seem surprising. For example, as a psychopharmacologist a doctor may act as a specialist adviser in relation to the service user being the recipient of advice. They may (skilfully and seamlessly) move into a more psychotherapeutic role relationship on other occasions. Working psychotherapeutically she may try to develop an observer-participant perspective: in other words, at

Table 1. Generalist $\boldsymbol{v}$. specialist roles

\begin{tabular}{lll} 
& Generalist roles & Specialist roles \\
\hline Example & General adult psychiatrist & Psychopharmacologist \\
& Care coordinator & Psychotherapist \\
Role perspective & Community mental health team & Advocate \\
& Best interests & Specialist adviser \\
Value orientation & Safety & Participant observer \\
Systemic position & Central & Growth, change \\
Assessment paradigm & Holistic & Peripheral
\end{tabular}


times empathically entering into the individual's selfexperience and at others helping them to observe themselves from a different, but more useful, perspective. This is not the same as keeping a simple best interest perspective. A psychotherapist may avoid simply offering advice but devise ways of creating selfreflection ('I wonder why you want me to offer you advice?'). An advocate (another form of mental health specialist role) would have a third-role perspective (neither 'best interest' nor 'participant observer' but more 'alter ego').

\section{Wider clinical implications}

To conclude, a care system without a properly developed generalist function will have something missing at its centre. This will have a number of consequences for its referral processing, its attachment patterns and for its supervisory functions. Systemically, a referral boundary (even in teams) is the functional division between a generalist and specialist role. With the referral goes a set of expectations that the other may be able to make a difference (e.g. therapeutically). The risk is that the referral system will never hold the service user in mind, because no one (no one in an oversight generalist role in the terms defined above) is left to do it, apart from the GP. Organisationally, the generalist role prevents patients ricocheting around a fragmented system and systemically promotes them being 'held in mind'. A psychologically minded care organisation ought at the very least to have this mind-minded approach. Professionals attempt to reproduce (or produce for the first time) some of the features of secure attachment on the assumption that that's a good way to produce the best health outcomes.

Case-management supervision should also focus on the issue of specialist and generalist roles. Who is holding the patient in mind and in what sort of role relationship? Are either of the poles of the structural value tension - safety and change - being overlooked or projected out of the care system? At an operational level this may mean looking at the risk assessment in a more psychological way in terms of role tensions (Undrill, 2007) and offering general adult psychiatrists better supervision. Consultant psychiatrists may put themselves at risk by not being given, or avoiding, emotionally intelligent generalist 'oversight' by a clinical manager (who would take a best interest perspective in their excessive case-loads) or the 'insight' of a specialist clinical supervisor (who could take into account the developmental needs of the consultant).

\section{Declaration of interest}

None.

\section{References}

BLOCH, S. \& GREEN, S. A. (2006) An ethical framework for psychiatry. Working for Psychiatrists: Enhancing LEPPING, P, STEINERT, GEBHARDT Effective Person-centred Services through NewWays of Working in Attitudes of mental health Multidisciplinary and Multiagency professionals and lay people towards Contexts. Department of Health.

involuntary admission and treatment in UNDRILL, G. (2007) The risks of risk England and Germany - a assessment. Advances in Psychiatric questionnaire analysis. European Treatment, 13, 291-297. Psychiatry, 19, 91-95.

PARSONS, T. (1951) The Social System. Free Press.

ROYAL COLLEGE OF PSYCHIATRISTS, NATIONAL INSTITUTE FOR MENTAL HEALTH IN ENGLAND, SUPPORTED BY

WOODBRIDGE, K. \& FULFORD, K.W. M. (2004) WhoseValues? A Workbook for Values Based Practice in Mental Health Care. Sainsbury Centre for Mental Health.

David Crossley Consultant Psychotherapist, Wrexham， *Peter Lepping Associate Medical Director, Consultant Psychiatrist and Honorary Senior Lecturer, University of Wales and North Wales NHS Trust, Wrexham Academic Unit, Technology Park, Wrexham, LL137TY, UK, email: peter.lepping@new-tr.wales. nhs.uk

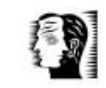

opinion \& debate 